\title{
Risk Evaluation of Electric Power Grid Enterprise Related to Electricity Transmission and Distribution Tariff Regulation Employing a Hybrid MCDM Model
}

\author{
Wenjin $\mathrm{Li}^{1}{ }^{1}$, Bingkang $\mathrm{Li}^{1}$, Rengcun Fang ${ }^{2}$, Peipei You ${ }^{3}$, Yuxin Zou ${ }^{2}$, Zhao $\mathrm{Xu}^{3}$ and Sen Guo ${ }^{1, *}$ \\ 1 School of Economics and Management, North China Electric Power University, Beijing 102206, China; \\ 120192206943@ncepu.edu.cn (W.L.); 1182106017@ncepu.edu.cn (B.L.) \\ 2 Economic and Technology Research Institute of State Grid Hubei Electric Power Company, \\ Wuhan 430077, China; fangrc@hb.sgcc.com.cn (R.F.); zouyx11@hb.sgcc.com.cn (Y.Z.) \\ 3 Department of Finance, Accounting and Auditing Research, State Grid Energy Research Institute, \\ Beijing 102209, China; youpeipei@sgeri.sgcc.com.cn (P.Y.); xuzhao@sgeri.sgcc.com.cn (Z.X.) \\ * Correspondence: guosen@ncepu.edu.cn or guosen324@163.com
}

\section{check for} updates

Citation: Li, W.; Li, B.; Fang, R.; You, P.; Zou, Y.; Xu, Z.; Guo, S. Risk Evaluation of Electric Power Grid Enterprise Related to Electricity Transmission and Distribution Tariff Regulation Employing a Hybrid MCDM Model. Mathematics 2021, 9, 989. https://doi.org/10.3390/ math9090989

Academic Editors: James Liou and Artūras Kaklauskas

Received: 15 March 2021

Accepted: 22 April 2021

Published: 28 April 2021

Publisher's Note: MDPI stays neutral with regard to jurisdictional claims in published maps and institutional affiliations.

Copyright: (C) 2021 by the authors Licensee MDPI, Basel, Switzerland. This article is an open access article distributed under the terms and conditions of the Creative Commons Attribution (CC BY) license (https:// creativecommons.org/licenses/by/ $4.0 /)$.

\begin{abstract}
In China, a new-round marketization reform of electricity industry is in progress, and the electricity transmission and distribution tariff reform is the core and important task. Currently, the electricity transmission and distribution tariff regulation has gone to the second round in China, and the electric power grid enterprises are facing a closed-loop regulatory system and an increasingly strict regulatory environment. Therefore, it is urgent to evaluate the risk of electric power grid enterprise that is related to electricity transmission and distribution tariff regulation, which can aid the electricity regulators and electric power grid enterprise operators to manage risk and promote the sustainable development of electric power industry. In this paper, a hybrid novel multi-criteria decision making (MCDM) method combining the fuzzy Best-Worst method (FBWM) and improved fuzzy comprehensive evaluation method based on a vague set is proposed for the risk evaluation of electric power grid enterprise related to electricity transmission and distribution tariff regulation. The risk evaluation index system is built. Subsequently, the FBWM is utilized to determine the optimal weights of electric power grid enterprise risk criteria, and the improved fuzzy comprehensive evaluation method that is based on vague set is employed to rank the comprehensive risk grade of electric power grid enterprise related to electricity transmission and distribution tariff regulation. The risk of a province-level electric power grid enterprise that is located in Northern China is empirically evaluated using the proposed MCDM method, and the result indicates that the overall risk of this province-level electric power grid enterprise belongs to 'High' grade, but it is very close to 'Very High' grade. The results indicate that the proposed hybrid novel MCDM method in this paper is effective and practical. Meanwhile, it provides a new view for the risk evaluation of electric power grid enterprise that is related to electricity transmission and distribution tariff regulation.
\end{abstract}

Keywords: electric power grid enterprise risk evaluation; electricity transmission and distribution tariff regulation; fuzzy Best-Worst model; improved fuzzy comprehensive evaluation method; vague set

\section{Introduction}

Since a new round of electric power system reform policy promulgated in 2015, several key fields' reforms have been comprehensively conducted in China, which include electricity transmission and distribution tariff, incremental distribution networks and electricity sales market, and the electricity transmission and distribution tariff reform is the core and important task for this round of electric power system reform [1,2]. The National Development and Reform Commission of China (NDRC) and related governmental departments have implemented the electricity transmission and distribution tariff reform 
pilots in some regions, such as Shenzhen city and Anhui province. Nowadays, China has accumulated more experience on the electricity transmission and distribution tariff regulation, and related regulatory measures have been improved and more targeted. By the year 2020, China has enacted two-round polices and measures that were related to the cost supervision and examination of electricity transmission and distribution tariff and the setting of electricity transmission and distribution tariff. Currently, the electricity transmission and distribution tariff regulation has entered a new period in China, but there are still some problems, such as imperfect rules and incomplete implementation of relevant policies [3]. With the greater clarified regulatory boundary and increasing force of regulation in China, the electric power grid enterprises are faced with a closed-loop regulatory system and increasingly strict regulatory environment, which will face more uncertain risks. Therefore, it is urgent to research the risks that are faced by the electricity power grid enterprise related to the current electricity transmission and distribution tariff regulation, which can help the electricity power grid enterprise operators to better grasp the risk and improve the risk management ability under electricity transmission and distribution tariff regulation environment.

Currently, most researches on the risks faced by electric power grid enterprise focus on the power grid operation, investment, and network security. For the operational risk, Zhou, et al. summarized the operational risk of China Southern Power Grid Corporation, such as the shutdown of High Voltage Direct Current Transmission (HVDC) bipolar block and the extreme climate in the southern area, which exposed the grid to the potential of destruction [4]. Wang, et al. divided the operational risks that are faced by the electric power grid enterprise into four aspects, including core resource, value creation, internal operation, and customer service [5]. Li, et al. proposed that it was necessary to establish a reasonable feed-in tariff system for wind power and strengthen the commercialization and marketization of wind power operation management, so as to cope with the operational risks that are faced by current power grid enterprises in the management of wind power projects [6]. For the investment risk, Hasda and Sumirat took the work accident as a vital factor for the electric power grid enterprise to obtain the electric investment project and manage its transmission assets [7]. Pop, et al. identified the technology of the company, the delay delivery of the electric facility, and the aging of transmission assets as the key factors that affect the Romanian electric power enterprises on their investment decision [8]. Lin, et al. believed that the implementation of energy conservation service projects of power grid enterprises will be mainly affected by the investment risk [9]. Sasaki and Nakayama evaluated a power transmission investment project between Ireland and the United Kingdom, and found that three main risks that are faced by grid enterprises, including the investment risk [10]. Bhattacharya and Kojima found that the investment risk faced by electric power grid enterprises could be resolved through portfolio risk optimization [11]. Duan, et al. proposed a hybrid multi-criteria decision-making method for risk evaluation of electric power grid investment in China under new socio-economic development situation, where the Bayesian best-worst method (BBWM) was used to weight the electric power grid investment risk criteria, and the improved matter-element extension model was employed to rank risk grade of electric power grid investment in China [12]. For the electric power grid, the network security risk also matters. Maziku, et al. stated that the IP-based communications will increase the likelihood of network attacks in smart grids, which will cause damages, such as wrong smart meter readings, impaired protection devices, and false demands for electricity, and then proposed a framework to assess security risks within a Software Defined Networking (SDN)-enabled smart grid communication network [13]. Cardenas, et al. proposed a cyber-physical model and risk assessment methodology for analyzing the emerging nexus between Internet of Thingsbased energy devices and the bulk transmission grid, and the result indicates that the current DER penetration rates are not yet significant enough to present serious risk [14]. The case suggested that electric power grid enterprises should timely update the internal security protection software, timing adjustment to the reaction mechanism of cyber-attacks, 
and remedial measures, in order to deal with the network security risk [15]. Onyeji, et al. believed that, as the integration of information technology of power infrastructure for electric power enterprises, they will potentially face more and more network attacks [16].

From the abovementioned literatures, it can be learnt that most of the current research focuses on the risks of operation, investment, and network security faced by the electric power grid enterprise. However, the risks that are faced by the electric power grid enterprise related to the governmental regulatory policy have been rarely studied, especially that the risks faced by the electric power grid enterprise related to the electricity transmission and distribution tariff regulation in China has not been studied to the best of our knowledge. In China, the electricity transmission and distribution tariff regulation has gone into the second round, and more strict rules, and procedures have been implemented. In this situation, the electric power grid enterprise will face more rigorous regulatory environment and related risks, and the risks that are faced by the electric power grid enterprise under the electricity transmission and distribution tariff regulation environment urgently need to be studied. Therefore, the risk evaluation of electric power grid enterprise under the electricity transmission and distribution tariff regulation environment will be conducted in this paper.

Facing the electricity transmission and distribution tariff regulation, the electric power grid enterprise will suffer multiple sources of risks, such as electricity transmission and distribution tariff compliance risk, electricity transmission and distribution tariff fluctuation risk, electricity transmission and distribution tariff execution risk, and electricity transmission and distribution tariff matching risk. Therefore, the risk evaluation of electric power grid enterprise that is related to electricity transmission and distribution tariff regulation belongs to a multi-criteria decision making (MCDM) issue. In this paper, a hybrid novel MCDM method is proposed for risk evaluation of electric power grid enterprise related to electricity transmission and distribution tariff regulation, which is composed of the fuzzy Best-Worst method (FBWM) and the improved fuzzy comprehensive evaluation method that is based on the vague set. When compared with the previous studies, there are two main contributions:

(1) The first contribution in this paper is unprecedentedly to propose a novel hybrid MCDM method for the risk evaluation of electric power grid enterprise related to electricity transmission and distribution tariff regulation, combining the fuzzy Best-Worst method (FBWM) and improved fuzzy comprehensive evaluation method based on vague set. The FBWM, which can consider the fuzziness and uncertainty of decision maker, is utilized to determine the weights of risk criteria of electric power grid enterprise related to electricity transmission and distribution tariff regulation, and the improved fuzzy comprehensive evaluation method based on the vague set, which can allow the experts not to evaluate the risk if they do not have enough knowledge to judge, is employed to rank the overall risk grade of electric power grid enterprise related to electricity transmission and distribution tariff regulation. Therefore, it can be said that the proposed hybrid novel MCDM method employed in this paper is the first time to be employed for the risk evaluation on electric power grid enterprise.

(2) The second contribution in this paper is to undertake the risk evaluation on electric power grid enterprise in a brand-new light. The risks that are related to the operation, investment, and network security of electric power grid have been paid more attention, but other factors under the circumstances of electricity transmission and distribution tariff reform have been neglected. While this paper innovatively pays significant attention to the risk faced by electric power grid enterprise related to another aspect, namely the electricity transmission and distribution tariff regulation, where few researches have been made on this filed. Therefore, this paper extends the risk scope of electric power grid enterprise, which can fill the research gap in this field. 
The rest of this paper is structured, as follows: Section 2 presents the literature review of the MCDM method; Section 3 builds the risk evaluation index system of electric power grid enterprise related to electricity transmission and distribution tariff regulation; Section 4 introduces the proposed hybrid novel MCDM method, including the FBWM and improved fuzzy comprehensive evaluation method based on vague set for risk evaluation on electric power grid enterprise related to electricity transmission and distribution tariff regulation; Section 5 conducts the empirical analysis and Section 6 discusses the results; and finally, Section 7 concludes this paper.

\section{Literature Review}

As this paper employs the MCDM method to undertake the risk evaluation of electric power grid enterprise related to electricity transmission and distribution tariff regulation, it is of significance to go through the researches concerning the MCDM method. Wang, et al. proposes an MCDM model combining the analytic hierarchy process (AHP), Supply Chain Operation Reference (SCOR) model, and the Data Envelopment Analysis (DEA) method to evaluate and obtain the optimal supplier in the oil industry [17]. Ghasempour, et al. use a wide variety multi-criteria decision making (MCDM) methods, which were investigated by various researchers, to figure out the effective criteria in selecting solar plants sites and solar plants technologies [18]. Wu, et al. employ a fuzzy MCDM technique based on cumulative prospect theory to select the most proper renewable power sources in China [19]. Lee, et al. take the comparative analysis of ranking renewable energy sources for electricity generation in Taiwan by applying four MCDM methods, which is WSM, VIKOR, TOPSIS, and ELECTRE [20]. Azhar, et al. take the Analytical Hierarchy Process (AHP) of the Multi-Criteria Decision-Making Analysis as a tool to rank the technical, economic, and environmental criteria of the renewable and conventional energy power plants [21]. Sedady and Beheshtinia employ the multi-criteria decision making (MCDM) method to obtain the priority of renewable power plants construction at the technical, economic, social, political, and environmental degrees [22].

While, in this paper, a new fuzzy-based MCDM method is employed, the FBWM is the extension of the basic Best-Worst method with consideration of the fuzziness of decision makers, which reduces the number of pairwise comparisons among criteria and improves the consistency of pairwise comparisons [23]. Because of the merits, the FBWM has been employed in many issues, such as the evaluation on service requirement of smart product service system [24], the selection of sustainable suppliers [25], national-scale landslide susceptibility mapping [26], and a strategy canvas drawing [27]. The fuzzy comprehensive evaluation method is also a commonly used MCDM method, which is based on the fuzzy set. When compared with the fuzzy set, the vague set can avoid the decision-making uncertainty that is caused by the subjective judgments and the inconsistency of knowledge reserve of decision makers, which can overcome the weakness of the traditional fuzzy set [28]. Because of these merits, the vague set has been employed in many practical issues, such as the evaluation of urban water security [29], power system black-start decisionmaking [30], onsite renewable energy technologies selection [31], and environmental impact evaluation of power grid projects in high altitude areas [32]. Accordingly, the fuzzy comprehensive evaluation method will be improved by using the vague set in this paper. Therefore, the FBWM will be used to weight the risk criteria of electric power grid enterprise related to electricity transmission and distribution tariff regulation, and the improved fuzzy comprehensive evaluation method based on vague set will be employed to rank the comprehensive risk grade of electric power grid enterprise that is related to electricity transmission and distribution tariff regulation in this paper. 


\section{Risk Evaluation Index System of Electric Power Grid Enterprise Related to Electricity Transmission and Distribution Tariff Regulation}

Nowadays, the electricity transmission and distribution tariff reform has entered a new stage, and the measures that are related to the cost supervision \& examination of electricity transmission and distribution tariff have been carried out in 2019. It guides the electric power grid enterprise to make rational and effective investment and reduce blind investment, clarify the items that cannot be included in the electricity transmission and distribution cost, further ensure the responsibility and obligation of electric power grid enterprises, enhance the requirements and procedures for information reporting, as well as the punishment for trust-breaking, so as to improve the quality and efficiency of information reporting. Meanwhile, a new version of the pricing method for transmission and distribution tariff at the provincial level has been implemented since September 2020. When compared with the former version, it comprehensively standardizes the pricing procedure and improves the pricing rules, and it is also the first time to realize the one-time full coverage of all provincial and regional electric power grid transmission and distribution tariff verification, in order to verify the theoretical transmission and distribution tariff of voltage division level, and to include the "network to network" transmission tariff into the provincial power grid verification price, which indicate the basic establishment of electricity transmission and distribution tariff regulation system and framework in China. In this situation, the electric power grid enterprise will face much stricter electricity transmission and distribution tariff regulation environment. Under these circumstances, the electric power grid enterprise has the potential risks of failing to meet the requirement of stricter electricity transmission and distribution tariff regulation.

Therefore, it is significant to build a proper evaluation index system, including a set of criteria, in order to evaluate the risk of electric power grid enterprise related to electricity transmission and distribution tariff regulation. The key and important risk criteria need to be in the risk evaluation index system, which can tell the core characteristics of risk faced by the electric power grid enterprise related to electricity transmission and distribution tariff regulation. In this paper, the risk evaluation index system of electric power grid enterprise related to electricity transmission and distribution tariff regulation includes four criteria, namely electricity transmission and distribution tariff compliance risk criterion, electricity transmission and distribution tariff fluctuation risk criterion, electricity transmission and distribution tariff execution risk criterion, and electricity transmission and distribution tariff matching risk criterion. Meanwhile, these four risk criteria are composed of several sub-criteria, respectively. The detailed and concrete decision-making process for electric power grid enterprise risk evaluation index system is shown above:

Firstly, an expert panel is set up to build the risk evaluation index system of electric power grid enterprise related to electricity transmission and distribution tariff regulation, which includes three managers in the electricity enterprise, three scholars majored in the transmission and distribution reform. Subsequently, according to the relevant electricity transmission and distribution tariff policies and expert panel's suggestion, four criteria are determined, including electricity transmission and distribution tariff compliance risk criterion (C1), electricity transmission and distribution tariff fluctuation risk criterion (C2), electricity transmission and distribution tariff execution risk criterion (C3), and electricity transmission and distribution tariff matching risk criterion (C4). Afterwards, the sub-criteria that are related to four risk criteria are initially selected, and expert panel reviews the initial sub-criteria, and then selects more important ones based on their own knowledge and experience. Finally, the risk criteria and sub-criteria for risk evaluation of electric power grid enterprise related to electricity transmission and distribution tariff regulation are determined. Figure 1 shows the risk evaluation index system of electric power grid enterprise related to electricity transmission and distribution tariff regulation, which includes four risk criteria and fifteen risk sub-criteria. 


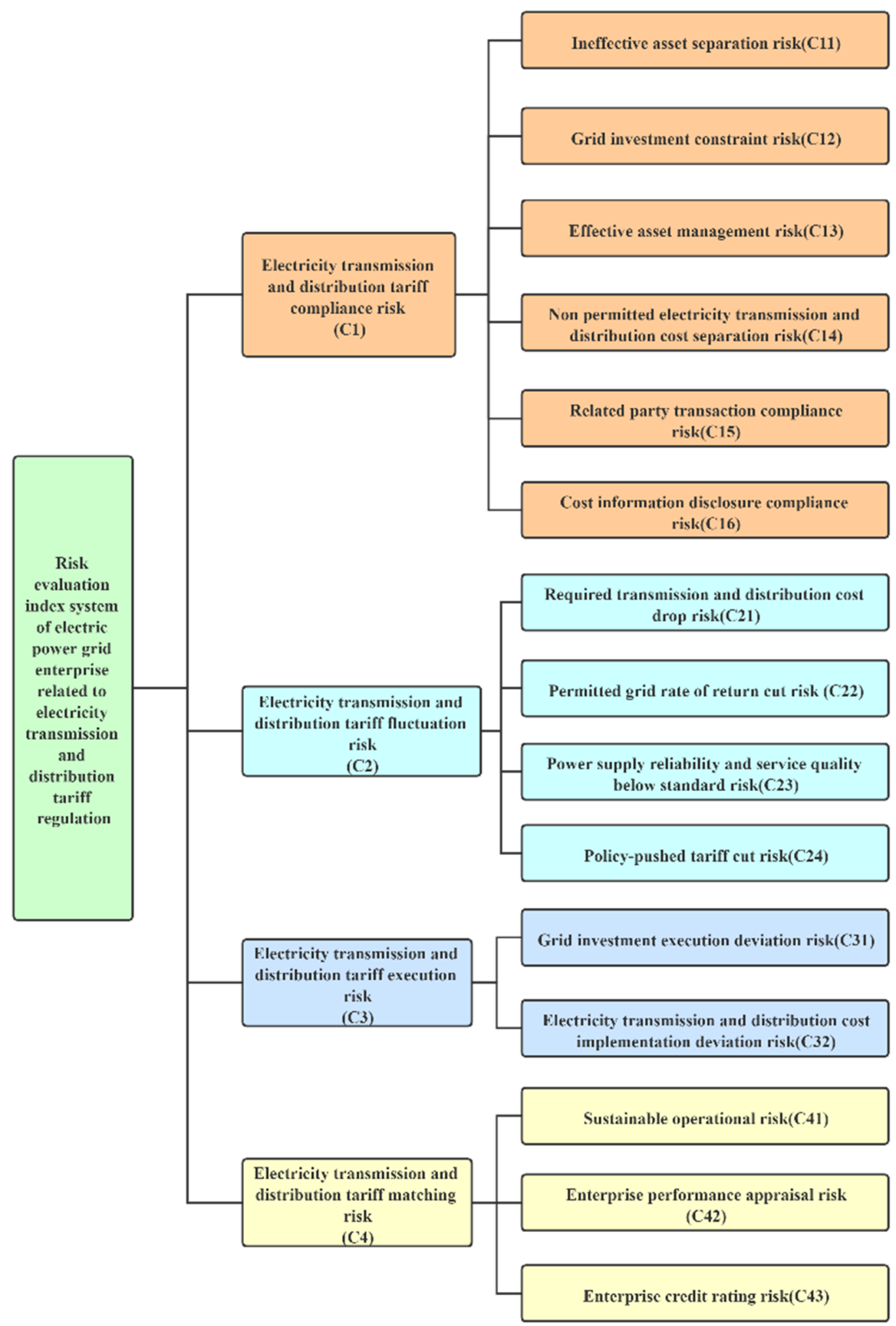

Figure 1. Risk evaluation index system of electric power grid enterprise related to electricity transmission and distribution tariff regulation.

For the electricity transmission and distribution tariff compliance risk, it means that the risk caused by the case that the electric power grid enterprise does not meet the requirements of the related electricity transmission and distribution tariff regulation policies in the tariff setting process. For this risk criterion, it includes six risk sub-criteria, namely ineffective asset separation risk sub-criterion (C11), grid investment constraint risk 
sub-criterion (C12), effective asset management risk sub-criterion (C13), non-permitted electricity transmission and distribution cost separation risk sub-criterion (C14), related party transaction compliance risk sub-criterion (C15), and cost information disclosure compliance risk sub-criterion (C16).

For the electricity transmission and distribution tariff fluctuation risk, it means that the risk caused by the case that the electricity transmission and distribution tariff level is changed significantly, which will pose a great impact on the normal business activities and financial viability of electric power grid enterprises. For this risk criterion, it includes four risk sub-criteria, namely the required transmission and distribution cost drop risk sub-criterion (C21), permitted grid rate of return cut risk sub-criterion (C22), power supply reliability and service quality below standard risk sub-criterion (C23), and policy-pushed tariff cut risk sub-criterion (C24).

For the electricity transmission and distribution tariff execution risk, it means the risk caused by the case that, in the practical tariff execution process, due to the changes of external environment, internal management, and other factors, the actual execution tariff may not be consistent with the initial verification level. For this risk criterion, it includes two risk sub-criteria, namely grid investment execution deviation risk sub-criterion (C31) and electricity transmission and distribution cost implementation deviation risk sub-criterion (C32).

For the electricity transmission and distribution tariff matching risk criterion, it means the risk that is caused by the case that the verification level of electricity transmission and distribution tariff in the future regulatory cycle should meet the needs of the longterm development of the electric power grid enterprise, the long-term requirements of the regulatory authorities for the electric power grid enterprise, and the demand of the continuous improvement of the electric power grid enterprise's credit level. For this risk criterion, it includes three risk sub-criteria, namely sustainable operational risk subcriterion (C41), enterprise performance appraisal risk sub-criterion (C42), and enterprise credit rating risk sub-criterion (C43).

\section{The Proposed MCDM Methodology for Risk Evaluation of Electric Power Grid Enterprise Related to Electricity Transmission and Distribution Tariff Regulation}

In this paper, the risk of electric power grid enterprise that is related to electricity transmission and distribution tariff regulation is evaluated considering four risk criteria and fifteen risk sub-criteria. In practice, there are high risks for some criteria and subcriteria of electric power grid enterprise related to electricity transmission and distribution tariff regulation, but other criteria and sub-criteria may hold low risk. Therefore, the risk levels among criteria and among sub-criteria may be conflicting for the risk evaluation of electric power grid enterprise related to electricity transmission and distribution tariff regulation, which need to be simultaneously considered for comprehensive risk evaluation of electric power grid enterprise related to electricity transmission and distribution tariff regulation. While the MCDM method acts as a significant role in figuring out the practical decisions faced with conflicting criteria, more importantly, scholars have applied the MCDM methods, including the TOPSIS, PROMETHEE, and Normalized Interval-Valued Triangular Fuzzy Numbers to solve many complex decision-making issues, which have been demonstrated as effective and accurate methods [33-35]. Therefore, a hybrid novel MCDM method is proposed and employed for comprehensive risk evaluation of electric power grid enterprise that is related to electricity transmission and distribution tariff regulation in this paper, which includes the FBWM for weight determination of risk criteria and improved fuzzy comprehensive evaluation method based on vague set for comprehensive risk ranking of electric power grid enterprise. The detailed theories of the proposed hybrid MCDM method in this paper are introduced in the following. 


\subsection{The FBWM for Weight Determination of Risk Criteria}

The weight of each risk criteria is particularly important for evaluating the risk of electric power grid enterprise that is related to electricity transmission and distribution tariff regulation. When there is only one electric power grid enterprise to be evaluated, each risk criterion only has one value, which results in the fact that the objective weighting method such as the variation coefficient method and entropy weight method cannot be used. Even if there are multiple electric power grid enterprises to be evaluated, the operating situations of different regional electric power grid enterprise in China are diversified, and then the risk criteria weight calculated by the above weighting methods will be changed according to the risk criteria values, which is not robust. Meanwhile, the risk criteria in this paper are qualitative, so it is inevitable to face the difficulty in determining the risk criteria values when the objective weighting method is used. Therefore, the subjective weighting method will be used in order to obtain reasonable risk criteria weights. The fuzzy Best-Worst method (FBWM) is a new subjective weighting method, which combines the Best-Worst method (BWM) and the fuzzy set theory [23]. When compared with the BWM, the FBWM can consider the fuzziness and uncertainty of decision makers, which has a higher consistency of pairwise comparison and has been employed in many practical issues, such as prioritization of failures [36], optimal combination of power plants alternatives [37], sustainable landfill site selection [38], and maintenance assessment in the hospitals [39]. The principles of the FBWM are listed as followed [23].

Suppose that the object of study includes $\mathrm{n}$ criteria, and decision makers can judge the important degree between the two criteria in the form of linguistic level relying on their knowledge and experience, such as important, weakly important, and very important. Subsequently, the linguistic level results can be transformed into triangular fuzzy number according to Table 1 [23]. Finally, the fuzzy comparison matrix $\widetilde{A}$ can be obtained, just as shown in Equation (1).

$$
\widetilde{A}=\begin{gathered}
c_{1} \\
c_{2} \\
\vdots \\
c_{n}
\end{gathered} \quad\left[\begin{array}{cccc}
\widetilde{a}_{11} & c_{2} & \cdots & \widetilde{a}_{12} \\
\widetilde{a}_{21} & \widetilde{a}_{22} & \cdots & \widetilde{a}_{1 n} \\
\vdots & \vdots & \ddots & \vdots \\
\widetilde{a}_{n 1} & \widetilde{a}_{n 2} & \cdots & \widetilde{a}_{n n}
\end{array}\right]
$$

where $\widetilde{a}_{i j}$ is the relative fuzzy preference of criterion $i$ to criterion $j$, which can be represented by a triangular fuzzy number.

Table 1. Transformation rules of linguistic variables of decision-makers.

\begin{tabular}{cc}
\hline Linguistic Terms & Membership Function \\
\hline Equally important (EI) & $(1,1,1)$ \\
Weakly important (WI) & $(2 / 3,1,3 / 2)$ \\
Fairly important (FI) & $(3 / 2,2,5 / 2)$ \\
Very important (VI) & $(5 / 2,3,7 / 2)$ \\
Absolutely important (AI) & $(7 / 2,4,9 / 2)$ \\
\hline
\end{tabular}

The specific steps of using the FBWM to determine the weights of risk criteria are described, as follows:

Step 1. Build the risk evaluation index system.

A reasonable evaluation index system is very important to the risk evaluation of electric power grid enterprise that is related to electricity transmission and distribution tariff regulation. It should be able to represent the basic characteristics of the risks faced by the electric power grid enterprise under the electricity transmission and distribution tariff regulation environment. The evaluation index system of electric power grid enterprise 
that is related to electricity transmission and distribution tariff regulation has been built in Section 2.

Step 2. Determine the best and worst risk criteria.

On the basis of the risk evaluation index system, the best risk criterion $c_{B}$ and the worst risk criterion $c_{W}$ should be determined according to the knowledge and experience of the decision-makers.

Step 3. Execute the fuzzy reference comparisons for the best risk criterion and worse risk criterion.

The decision makers make pairwise comparisons between the best risk criterion and other risk criteria in the risk evaluation index system by employing the linguistic terms in Table 1, and the fuzzy preferences of the best risk criterion over other risk criteria can be determined. Subsequently, the obtained fuzzy preferences are transformed to triangular fuzzy numbers using the transformation rules shown in Table 1. Finally, the fuzzy Best-to-Others vector $\widetilde{A}_{B}$ can be obtained as:

$$
\widetilde{A}_{B}=\left(\widetilde{a}_{B 1}, \widetilde{a}_{B 2}, \ldots, \widetilde{a}_{B n}\right)
$$

Meanwhile, the pairwise comparisons between the worst risk criterion and other risk criteria in the risk evaluation index system can also be conducted, and similar to $\widetilde{A}_{B}$, the fuzzy Others-to-Worse vector $\widetilde{A}_{W}$ can be obtained as:

$$
\widetilde{A}_{W}=\left(\widetilde{a}_{1 W}, \widetilde{a}_{2 W}, \ldots, \widetilde{a}_{n W}\right)
$$

Step 4. Determine the optimal fuzzy weights $\left(\widetilde{w}_{1}^{*}, \widetilde{w}_{2}^{*}, \ldots, \widetilde{w}_{n}^{*}\right)$ The ratio of the optimal fuzzy weight of the best risk criterion $\widetilde{w}_{B}$ and the optimal fuzzy weighted of other risk criteria $\widetilde{w}_{j}$ should be consistent with the fuzzy Best-to-Others vector $\widetilde{A}_{B}$. Meanwhile, the ratio of the optimal fuzzy weight of other risk criteria $\widetilde{w}_{j}$ and the optimal fuzzy weights of the worst risk criterion $\widetilde{w}_{W}$ should be consistent with the fuzzy Others-to-Worse vector $\widetilde{A}_{W}$. According to these principles, a min-max problem with constraint conditions can be built, as shown in Equation (4):

$$
\begin{array}{r}
\min \max _{j}\left\{\left|\frac{\widetilde{w}_{B}}{\widetilde{w}_{j}}-\widetilde{a}_{B j}\right|,\left|\frac{\widetilde{w}_{j}}{\widetilde{w}_{W}}-\widetilde{a}_{j W}\right|\right\} \\
\operatorname{s.t.}\left\{\begin{array}{c}
\sum_{j=1}^{n} R\left(\widetilde{w}_{j}\right)=1 \\
l_{j}^{w} \leq m_{j}^{w} \leq u_{j}^{w} \\
l_{j}^{w} \geq 0 \\
j=1,2, \ldots, n
\end{array}\right.
\end{array}
$$

which $\widetilde{w}_{B}=\left(l_{B}^{w}, m_{B}^{w}, u_{B}^{w}\right), \widetilde{w}_{j}=\left(l_{j}^{w}, m_{j}^{w}, u_{j}^{w}\right), \widetilde{w}_{W}=\left(l_{W}^{w}, m_{W}^{w}, u_{W}^{w}\right), \widetilde{a}_{B j}=\left(l_{B j}, m_{B j}, u_{B j}\right)$, $\tilde{a}_{j W}=\left(l_{j W}, m_{j W}, u_{j W}\right) ; R\left(\widetilde{w}_{j}\right)$ represents that the fuzzy weight value of risk criterion $j$ is transformed into an exact value, and it can be obtained by the Equation (5):

$$
R\left(\widetilde{w}_{j}\right)=\frac{l_{j}^{w}+4 m_{j}^{w}+u_{j}^{w}}{6}
$$


The Equation (4) can be transformed into a nonlinear constrained optimization problem, as shown in Equation (6):

$$
\text { s.t. }\left\{\begin{array}{c}
\min \widetilde{\xi} \\
\left|\frac{\widetilde{w}_{B}}{\widetilde{w}_{j}}-\widetilde{a}_{B j}\right| \leq \widetilde{\xi} \\
\left|\frac{\widetilde{w}_{j}}{\widetilde{w}_{W}}-\widetilde{a}_{j W}\right| \leq \widetilde{\xi} \\
\sum_{j=1}^{n} R\left(\widetilde{w}_{j}\right)=1 \\
l_{j}^{w} \leq m_{j}^{w} \leq u_{j}^{w} \\
l_{j}^{w} \geq 0 \\
j=1,2, \ldots, n
\end{array}\right.
$$

In Equation (6), because $l^{\tilde{5}} \leq m^{\xi} \leq u^{\xi}$, so let $\widetilde{\zeta}^{*}=\left(k^{*}, k^{*}, k^{*}\right), k^{*} \leq l^{\tilde{\xi}}$, and Equation (6) can be transformed into the following equation:

$$
\text { s.t. }\left\{\begin{array}{c}
\left|\frac{\left(l_{B}^{w}, m_{B}^{w}, u_{B}^{w}\right)}{\left(l_{j}^{w}, m_{j}^{w}, u_{j}^{w}\right)}-\left(l_{B j}, m_{B j}, u_{B j}\right)\right| \leq\left(k^{*}, k^{*}, k^{*}\right) \\
\left|\frac{\left(l_{j}^{w}, m_{j}^{w}, u_{j}^{w}\right)}{\left(l_{W}^{w}, m_{W}^{w}, u_{W}^{w}\right)}-\left(l_{j W}, m_{j W}, u_{j W}\right)\right| \leq\left(k^{*}, k^{*}, k^{*}\right) \\
\sum_{j=1}^{n} R\left(\widetilde{w}_{j}\right)=1 \\
l_{j}^{w} \leq m_{j}^{w} \leq u_{j}^{w} \\
l_{j}^{w} \geq 0 \\
j=1,2, \ldots, n
\end{array}\right.
$$

Finally, the optimal fuzzy weights of risk criteria $W=\left(\widetilde{w}_{1}^{*}, \widetilde{w}_{2}^{*}, \ldots, \widetilde{w}_{n}^{*}\right)$ can be obtained according to Equation (7).

\subsection{The Improved Fuzzy Comprehensive Evaluation Method for Risk Ranking of Electric Power grid Enterprise}

While the risk of electric power grid enterprise that is related to electricity transmission and distribution tariff regulation is evaluated, there exists information uncertainties, and the fuzzy comprehensive evaluation method can solve the problem well. However, the traditional fuzzy comprehensive evaluation method may lead to the distortion of ranking result, because its membership degree does not meet the additivity, and some information may be missing in the evaluation process [40]. The vague set has the obvious feature and advantage in that it can give the evidence of agreement and disagreement, so it can tell fuzzy information more comprehensively [41]. Therefore, an improved fuzzy comprehensive evaluation method that is based on the vague set is employed in this paper.

Vague set serves as an extension of fuzzy set. For the fuzzy set, it assumes that the membership degree can be taken into $[0,1]$ interval, but the vague set assumes that the membership degree of each element can be split into two portions, which are called support and opposition, respectively [31]. It tells that the membership degree should include both true and false membership degree, which is $t$ and $f$, respectively. Assuming that $U$ serves as a domain of discussion, in which $x$ represents any one element, the true and false membership function, $t_{A}$ and $f_{A}$, can stand for a vague set in $U$. Moreover, $t_{A}(x)$ serves as the lower boundary of the supporting membership degree of $x$ according to the evidence favoring $x$, while $f_{A}(x)$ is the opposite, it belongs to the lower boundary of the negative membership degree of $x$ according to the evidence against $x$, and $1-t_{A}(x)-f_{A}(x)$ represents the uncertainty. For the convenience of discussion, in this paper, it takes $t_{A}(x)$ as $t_{x}$ and $f_{A}(x)$ as $f_{x}$. It is evident that $t_{x}+f_{x} \leq 1$. Provided that $t_{x}=1-f_{x}$, the vague set 
will be transformed into fuzzy set, and provided that $t_{x}=1-f_{x}=0$ or $t_{x}=1-f_{x}=1$, the vague set will be transformed into a normal set [32].

The steps of using the improved fuzzy comprehensive evaluation method that is based on the vague set to evaluate the risk of electric power grid enterprise related to electricity transmission and distribution tariff regulation are introduced, as follows.

Step 1. Set the evaluation comment set with different levels for risk criteria. The comment set is $V=\left(V_{1}, V_{2}, V_{3}, V_{4}, V_{5}\right)$, which respectively represent 'Very low' risk, 'Low' risk, 'Middle' risk, 'High' risk, and 'Very high' risk.

Step 2. Build the vague set evaluation matrix. Experts are invited to judge all of the risk criteria according to the given comment set. $C_{i}$ represents the risk criteria, the comment set is $V_{j}(j=1,2,3,4,5)$, and an evaluation matrix $R$ of vague set can be built as:

$$
R=\left(\begin{array}{cccc}
r_{11} & r_{12} & \cdots & r_{1 n} \\
r_{21} & r_{22} & \cdots & r_{2 n} \\
\vdots & \vdots & \ddots & \vdots \\
r_{n 1} & r_{n 2} & \cdots & r_{n n}
\end{array}\right)
$$

where $r_{i j}$ is the vague value of $C_{i}$ on the comment level $V_{j}$, and there is $r_{i j}=\left[t_{A}, 1-f_{A}\right]$. Invite the experts to judge each risk criteria according to the comment set. Experts can give up voting to better tell the degree of hesitation from the experts. For example, there are 10 experts evaluating certain risk criteria of electric power grid enterprise related to electricity transmission and distribution tariff regulation. If four experts think that it is at very low risk, three experts tell that it is at low risk, two experts say the risk is normal, and 1 expert gives up the judgment, then the following result can be obtained:

$$
r_{i}=\left(r_{i 1}, r_{i 2}, r_{i 3}, r_{i 4}, r_{i 5}\right)=[(0.4,0.5),(0.3,0.4),(0.2,0.3),(0,0.1),(0,0.1)]
$$

Step 3. Undertake the comprehensive evaluation based on the vague set evaluation matrix $R$ and index system weights $W$ [32]:

$$
\begin{gathered}
F=W \otimes R=\left(F_{1}, F_{2}, F_{3}, F_{4}, F_{5}\right) \\
F_{j}=\left(w_{1} \otimes r_{1 j}\right) \oplus\left(w_{2} \otimes r_{2 j}\right) \oplus \ldots \oplus\left(w_{n} \otimes r_{n j}\right), j=1,2,3,4,5
\end{gathered}
$$

where $F$ represents the comprehensive evaluation result. $F_{j}$ represents the vague value of the object, which is calculated on the comment set $V_{j}, \otimes$ and $\oplus$, respectively, represent the operational symbol of multiplication and finite sum of vague set. When $k$ serves as the real number on $[0,1]$ interval, $A$ and $B$ stand for elements on vague set, where $A=\left[t_{A}, 1-f_{A}\right]$ and $B=\left[t_{B}, 1-f_{B}\right]$, then two equations are shown above [32]:

$$
\begin{gathered}
k \otimes A=\left[k t_{A}, k\left(1-f_{A}\right)\right] \\
A \oplus B=\left[\min \left\{1, t_{A}+t_{B}\right\}, \min \left\{1,\left(1-f_{A}\right)+\left(1-f_{B}\right)\right\}\right]
\end{gathered}
$$

Because the vague value is an interval number, the relative scoring function, as shown in Equation (13), is used to obtain its real number [32].

$$
J(x)=\frac{t_{x}}{t_{x}+f_{x}}
$$

Finally, each comment is given a score, that is $V=\left(V_{1}, V_{2}, V_{3}, V_{4}, V_{5}\right)=$ $(20,40,60,80,100)$. According to the scoring function of each comment, the weighted average operator is used to rank the comprehensive risk of electric power grid enterprise that is related to electricity transmission and distribution tariff regulation.

When using the FBWM to determine the weight of criterion, it is of great importance to test the similarity between the ranking of ranking importance of criteria. In this paper, the WS coefficient is applied, and the concrete equation is as follows [42]:

$$
W S=1-\sum_{i=1}^{n}\left(2^{-x i} \cdot\left(\frac{\left|R_{x i}-R_{y i}\right|}{\max \left\{\left|1-R_{x i}, N-R_{x i}\right|\right\}}\right)\right)
$$


where WS is a value of similarity coefficient, $N$ is a length of ranking, and $R_{x i}$ and $R_{y i}$ mean the place in the ranking for $i$-th element in, respectively, ranking $x$ and ranking $y$.

When the WS is less than 0.234 , it obtains the low similarity. When the WS is larger than 0.808 , it gets the high similarity. While the WS stays from 0.352 to 0.689 , it obtains the medium similarity. Figure 2 shows detailed definitions of the WS [42].

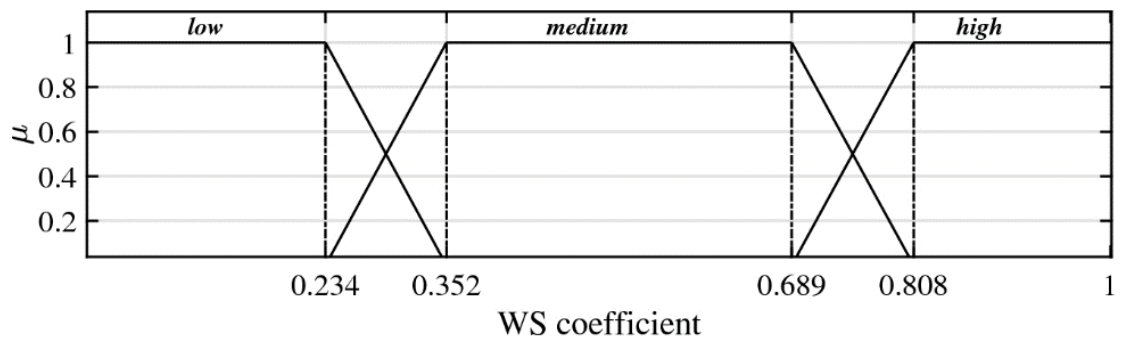

Figure 2. The concepts of different similarity of rankings by using trapezoidal fuzzy numbers [42].

\subsection{The Framework of Risk Evaluation of Electric Power Grid Enterprise Related to Electricity} Transmission and Distribution Tariff Regulation

In this paper, the hybrid novel MCDM method for the risk evaluation of electric power grid enterprise related to electricity transmission and distribution tariff regulation is proposed combining the FBWM and improved fuzzy comprehensive evaluation method based on the vague set. The FBWM is employed to figure out the weights of risk criteria that take the fuzziness of preferences of decision makers into account. The fuzzy comprehensive evaluation method improved by the vague set is employed to rank the comprehensive risk grade of electric power grid enterprise related to electricity transmission and distribution tariff regulation, which can avoid evaluation information loss and overcome the weakness of the traditional fuzzy comprehensive evaluation method based on the fuzzy set. Therefore, the risk ranking result of electric power grid enterprise that is related to electricity transmission and distribution tariff regulation by using the hybrid MCDM method containing the FBWM and improved fuzzy comprehensive evaluation method based on the vague set is more effective and appropriate.

Figure 3 shows the detailed procedure of the hybrid MCDM method for risk evaluation of electric power grid enterprise related to electricity transmission and distribution tariff regulation in this paper.

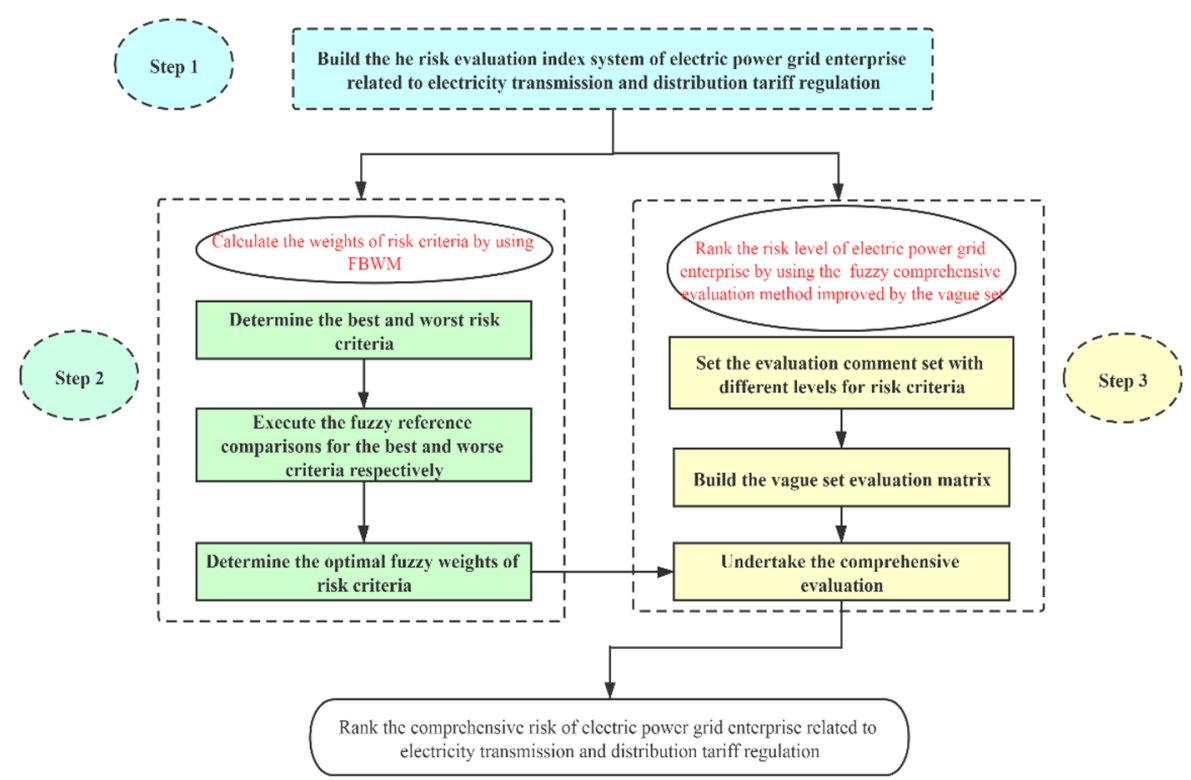

Figure 3. The framework of risk evaluation of electric power grid enterprise related to electricity. 


\section{Empirical Analysis}

In this section, a province-level electric power grid enterprise that is located in Northern China is selected as a practical case. The risk of this electric power grid enterprise related to electricity transmission and distribution tariff regulation will be evaluated by using the proposed MCDM method, where the FBWM is used to weight the risk criteria and the improved fuzzy comprehensive evaluation method that is based on the vague set is employed to rank the risk level of this electric power grid enterprise.

\subsection{Determine the Weights of Risk Criteria of Electric Power Grid Enterprise}

Firstly, the expert panel is invited again for risk criteria weight determination. Among the four risk criteria, including electricity transmission and distribution tariff compliance risk criterion (C1), electricity transmission and distribution tariff fluctuation risk criterion (C2), electricity transmission and distribution tariff execution risk criterion (C3), and electricity transmission and distribution tariff matching risk criterion (C4), the best criterion is electricity transmission and distribution tariff compliance risk (C1) based on the judgement of expert panel, and the worst criterion is electricity transmission and distribution tariff execution risk (C3). Table 2 lists the linguistic terms for fuzzy preferences of the best risk criterion over other risk criteria and Table 3 lists the linguistic terms for fuzzy preferences of all other risk criteria over the worst risk criterion.

Table 2. The linguistic terms for fuzzy preferences of the best risk criterion over other risk criteria.

\begin{tabular}{clll}
\hline Criteria & C2 & C3 & C4 \\
\hline The best risk criterion C1 & VI & AI & VI \\
\hline
\end{tabular}

Table 3. The linguistic terms for fuzzy preferences of all other risk criteria over the worst risk criterion.

\begin{tabular}{cc}
\hline Criteria & The Worse Risk Criterion C3 \\
\hline C1 & AI \\
C2 & FI \\
C4 & WI \\
\hline
\end{tabular}

According to the comparison results of the best and worst risk criteria with other risk criteria, the fuzzy comparison vectors that correspond to the best and worst risk criteria can be obtained as:

$$
\begin{aligned}
& \widetilde{A}_{B}=\left[(1,1,1),\left(\frac{5}{2}, 3, \frac{7}{2}\right),\left(\frac{7}{2}, 4, \frac{9}{2}\right),\left(\frac{5}{2}, 3, \frac{7}{2}\right)\right] \\
& \widetilde{A}_{W}=\left[\left(\frac{7}{2}, 4, \frac{9}{2}\right),\left(\frac{3}{2}, 2, \frac{5}{2}\right),(1,1,1),\left(\frac{2}{3}, 1, \frac{3}{2}\right)\right]
\end{aligned}
$$

According to Equation (7) and the above two fuzzy comparison vectors, the optimal fuzzy weights vectors of four risk criteria can be obtained as:

$$
\begin{gathered}
\widetilde{W}_{1}^{*}=(0.5115,0.5196,0.5279) ; \widetilde{W}_{2}^{*}=(0.1646,0.1964,0.2368) ; \\
\widetilde{W}_{3}^{*}=(0.1095,0.1193,0.1411) ; \widetilde{W}_{4}^{*}=(0.1399,0.1583,0.194)
\end{gathered}
$$

Subsequently, the optimal weights of four risk criteria can be calculated using the Equation (5), and the results are:

$$
W_{1}^{*}=0.5197 ; W_{2}^{*}=0.1978 ; W_{3}^{*}=0.1213 ; W_{4}^{*}=0.1612
$$

Similar to the weight determination of risk criteria, the risk sub-criteria that are related to each risk criteria can also be weighted. According to the opinion of expert panel, the best and worst risk sub-criteria related to each risk criteria can be determined, which are shown in Table 4. 
Table 4. The best and worst risk sub-criteria related to each risk criteria.

\begin{tabular}{ccc}
\hline Related to Criteria & The Best Sub-Criterion & The Worst Sub-Criterion \\
\hline C1 & C12 & C14 \\
C2 & C21 & C24 \\
C3 & C32 & C31 \\
C4 & C41 & C42 \\
\hline
\end{tabular}

Table 5 lists the linguistic terms for fuzzy preferences of the best risk sub-criterion over other risk sub-criteria, and Table 6 lists the linguistic terms for fuzzy preferences of other risk sub-criteria over the worst risk sub-criterion.

Table 5. The linguistic terms for fuzzy preferences of the best risk sub-criterion over other risk sub-criteria.

\begin{tabular}{|c|c|c|c|c|c|c|c|c|c|c|c|}
\hline The Best Risk Sub-Criterion & C11 & C13 & C14 & C15 & C16 & $\mathrm{C} 22$ & $\mathrm{C} 23$ & $\mathrm{C} 24$ & C31 & $\mathrm{C} 42$ & $\mathrm{C} 43$ \\
\hline $\mathrm{C} 12$ & VI & WI & $\mathrm{AI}$ & VI & FI & - & - & - & - & - & - \\
\hline C21 & - & - & - & - & - & $\mathrm{AI}$ & VI & $\mathrm{AI}$ & - & - & - \\
\hline C32 & - & - & - & - & - & - & - & - & AI & - & - \\
\hline C41 & - & - & - & - & - & - & - & - & - & AI & VI \\
\hline
\end{tabular}

Table 6. The linguistic terms for fuzzy preferences of other risk sub-criteria over the worst risk sub-criterion.

\begin{tabular}{ccccc}
\hline The Worst Risk Sub-Criterion & C14 & C24 & C31 & C42 \\
\hline C11 & VI & - & - & - \\
C12 & AI & - & - & - \\
C13 & WI & - & - & - \\
C15 & VI & - & - & - \\
C16 & FI & - & - & - \\
C21 & - & AI & - & - \\
C22 & - & FI & - & - \\
C23 & - & VI & - & - \\
C32 & - & - & AI & - \\
C41 & - & - & - & VI \\
C43 & - & - & - & VI \\
\hline
\end{tabular}

According to Tables 5 and 6 , the fuzzy comparison vectors that correspond to the best and worst risk sub-criteria can be determined, as follows.

The fuzzy comparison vectors of risk sub-criteria related to risk criterion $\mathrm{C} 1$ are:

$$
\begin{gathered}
\widetilde{A}_{B}=\left[\left(\frac{5}{2}, 3, \frac{7}{2}\right),(1,1,1),\left(\frac{5}{2}, 2.5, \frac{7}{2}\right),\left(\frac{7}{2}, 4, \frac{9}{2}\right),\left(\frac{5}{2}, 3, \frac{7}{2}\right),\left(\frac{7}{2}, 4, \frac{9}{2}\right)\right] \\
\widetilde{A}_{W}=\left[\left(\frac{7}{2}, 4, \frac{9}{2}\right),\left(\frac{7}{2}, 4, \frac{9}{2}\right),\left(\frac{3}{2}, 2, \frac{5}{2}\right),(1,1,1),\left(\frac{5}{2}, 3, \frac{7}{2}\right),\left(\frac{5}{2}, 3, \frac{7}{2}\right)\right]
\end{gathered}
$$

The fuzzy comparison vectors of risk sub-criteria related to risk criterion $\mathrm{C} 2$ are:

$$
\begin{aligned}
& \widetilde{A}_{B}=\left[(1,1,1),\left(\frac{7}{2}, 4, \frac{9}{2}\right),\left(\frac{5}{2}, 3, \frac{7}{2}\right),\left(\frac{7}{2}, 4, \frac{9}{2}\right)\right] \\
& \widetilde{A}_{W}=\left[\left(\frac{7}{2}, 4, \frac{9}{2}\right),\left(\frac{3}{2}, 2, \frac{5}{2}\right),\left(\frac{5}{2}, 3, \frac{7}{2}\right),(1,1,1)\right]
\end{aligned}
$$

The fuzzy comparison vectors of risk sub-criteria related to risk criterion $\mathrm{C} 3$ are:

$$
\begin{aligned}
& \widetilde{A}_{B}=\left[\left(\frac{7}{2}, 4, \frac{9}{2}\right),(1,1,1)\right] \\
& \widetilde{A}_{W}=\left[(1,1,1),\left(\frac{7}{2}, 4, \frac{9}{2}\right)\right]
\end{aligned}
$$

The fuzzy comparison vectors of risk sub-criteria related to risk criterion $\mathrm{C} 4$ are:

$$
\begin{aligned}
\widetilde{A}_{B} & =\left[(1,1,1),\left(\frac{7}{2}, 4, \frac{9}{2}\right),\left(\frac{5}{2}, 3, \frac{7}{2}\right]\right. \\
\widetilde{A}_{W} & =\left[\left(\frac{5}{2}, 3, \frac{7}{2}\right),(1,1,1),\left(\frac{5}{2}, 3, \frac{7}{2}\right)\right]
\end{aligned}
$$


According to the above fuzzy comparison vectors of risk sub-criteria related to each risk criteria and Equation (7), the optimal fuzzy weights vectors of the risk sub-criteria that are related to each risk criteria can be obtained, as follows:

The optimal fuzzy weights vectors of six risk sub-criteria that are related to risk criterion $\mathrm{C} 1$ are:

$$
\begin{gathered}
\widetilde{W}_{11}^{*}=(0.1595,0.1886,0.2403) ; \widetilde{W}_{12}^{*}=(0.3304,0.3432,0.3637) ; \\
\widetilde{W}_{13}^{*}=(0.0903,0.1189,0.1896) ; \widetilde{W}_{14}^{*}=(0.0636,0.0665,0.07) ; \\
\widetilde{W}_{15}^{*}=(0.1089,0.1431,0.2171) ; \widetilde{W}_{16}^{*}=(0.0972,0.1207,0.1449) ;
\end{gathered}
$$

The optimal fuzzy weights vectors of four risk sub-criteria that are related to risk criterion $\mathrm{C} 2$ are:

$$
\begin{aligned}
& \widetilde{W}_{21}^{*}=(0.4872,0.5124,0.5372) ; \widetilde{W}_{22}^{*}=(0.1149,0.144,0.1774) ; \\
& \widetilde{W}_{23}^{*}=(0.197,0.2337,0.2821) ; \widetilde{W}_{24}^{*}=(0.1021,0.1066,0.115) ;
\end{aligned}
$$

The optimal fuzzy weights vectors of two risk sub-criteria related to risk criterion C3 are:

$$
\widetilde{W}_{31}^{*}=(0.1889,0.1998,0.2144) ; \widetilde{W}_{32}^{*}=(0.7505,0.7902,0.8502) ;
$$

The optimal fuzzy weights vectors of three risk sub-criteria related to risk criterion C4 are:

$$
\begin{gathered}
\widetilde{W}_{41}^{*}=(0.5634,0.6001,0.6298) ; \widetilde{W}_{42}^{*}=(0.1198,0.1248,0.1341) ; \\
\widetilde{W}_{43}^{*}=(0.2302,0.2737,03282)
\end{gathered}
$$

According to the above optimal fuzzy weight vectors of risk sub-criteria and Equation (5), the optimal weights of the risk sub-criteria related to each risk criterion can be calculated, as follows:

The optimal weights of six risk sub-criteria related to risk criterion $\mathrm{C} 1$ are:

$$
W_{11}^{*}=0.1924 ; W_{12}^{*}=0.3446 ; W_{13}^{*}=0.1259 ; W_{14}^{*}=0.0667 ; W_{15}^{*}=0.1497 ; W_{16}^{*}=0.1208
$$

The optimal weights of four risk sub-criteria related to risk criterion $\mathrm{C} 2$ are:

$$
W_{21}^{*}=0.5123 ; W_{22}^{*}=0.1447 ; W_{23}^{*}=0.2357 ; W_{24}^{*}=0.1073
$$

The optimal weights of two risk sub-criteria related to risk criterion C3 are:

$$
W_{31}^{*}=0.2004 ; W_{32}^{*}=0.7996
$$

The optimal fuzzy weights vectors of three risk sub-criteria that are related to risk criterion $\mathrm{C} 4$ are:

$$
W_{41}^{*}=0.599 ; W_{42}^{*}=0.1255 ; W_{43}^{*}=0.2755
$$

5.2. Rank Risk Grade of Province-Level Electric Power Grid Enterprise Related to Electricity Transmission and Distribution Tariff Regulation

The expert panel evaluates the risk level of all the sub-criteria and obtains the corresponding vague set evaluation matrix for four risk criteria, which are shown, as follows:

$$
R_{1}=\left(\begin{array}{ccccc}
(0,0.1) & (0,0.1) & (0.2,0.3) & (0.3,0.4) & (0.4,0.5) \\
(0,0) & (0,0) & (0.2,0.2) & (0.3,0.3) & (0.5,0.5) \\
(0,0) & (0,0) & (0.3,0.3) & (0.4,0.4) & (0.3,0.3) \\
(0,0.1) & (0.3,0.4) & (0.3,0.4) & (0.3,0.4) & (0,0.1) \\
(0,0.1) & (0,0.1) & (0.3,0.4) & (0.3,0.4) & (0.3,0.4) \\
(0,0) & (0,0) & (0.2,0.2) & (0.5,0.5) & (0.3,0.3)
\end{array}\right)
$$




$$
\begin{aligned}
R_{2}= & \left(\begin{array}{ccccc}
(0,0) & (0.1,0.1) & (0.2,0.2) & (0.3,0.3) & (0.4,0.4) \\
(0,0.1) & (0.2,0.3) & (0.4,0.5) & (0.1,0.2) & (0.2,0.3) \\
(0,0) & (0,0) & (0.3,0.3) & (0.3,0.3) & (0.4,0.4) \\
(0,0) & (0.3,0.3) & (0.3,0.3) & (0.3,0.3) & (0.1,0.1)
\end{array}\right) \\
& R_{3}=\left(\begin{array}{ccccc}
(0,0) & (0,0) & (0.3,0.3) & (0.4,0.4) & (0.3,0.3) \\
(0,0.1) & (0,0.1) & (0.5,0.6) & (0.2,0.3) & (0.2,0.3)
\end{array}\right) \\
R_{4}= & \left(\begin{array}{ccccc}
(0,0) & (0,0) & (0.4,0.4) & (0.3,0.3) & (0.3,0.3) \\
(0,0) & (0.1,0.1) & (0.4,0.4) & (0.3,0.3) & (0.2,0.2) \\
(0,0) & (0,0) & (0.4,0.4) & (0.4,0.4) & (0.2,0.2)
\end{array}\right)
\end{aligned}
$$

According to the optimal weights of the risk sub-criteria and the above vague set evaluation matrix of four risk criteria, the risk grade for risk criteria can be calculated, as follows:

$$
\begin{gathered}
F_{1}=(0,0.0204,0.2643,0.35110 .3642) \\
F_{2}=(0,0.1023,0.2671,0.275,0.3556) \\
F_{3}=(0,0.0 .4999,0.2609,0.2392) \\
F_{4}=(0,0.0125,0.4,0.3276,0.2599)
\end{gathered}
$$

Subsequently, combining the scoring function of each comment $V=\left(V_{1}, V_{2}, V_{3}, V_{4}, V_{5}\right)$ $=(20,40,60,80,100)$ and the weights of four risk criteria, the risk scoring of our risk criteria can be calculated, as follows:

$$
S_{1}=(81.95,77.68,74.79,76.7)
$$

Finally, the total risk scoring of this province-level electric power grid enterprise that is related to electricity transmission and distribution tariff regulation is:

$$
S_{T}=\left(\mathrm{W}_{1}^{*}, \mathrm{~W}_{2}^{*}, \mathrm{~W}_{3}^{*}, \mathrm{~W}_{4}^{*}\right) * S_{1}^{T}=79.39
$$

Therefore, it can be seen that the risk degree of this province-level electric power grid enterprise related to electricity transmission and distribution tariff regulation belongs to 'High'. Meanwhile, among four risk criteria, the electricity transmission and distribution tariff compliance risk are at a relatively high level. Therefore, this province-level electric power grid enterprise should pay greater attention to this risk.

\section{Discussion}

\subsection{Result Analysis}

This paper proposed a hybrid novel MCDM method combining the FBWM and the improved fuzzy comprehensive evaluation method based on vague set in order to evaluate the risk of electric power grid enterprise related to electricity transmission and distribution tariff regulation, and the result indicates that the overall risk grade of this province-level electric power grid enterprise under current electricity transmission and distribution tariff regulation environment belongs to 'High'. The weights and performances of risk criteria and sub-criteria will be discussed in detail in order to analyze the risk ranking result in depth.

Among four risk criteria, the weight of electricity transmission and distribution tariff compliance risk $(\mathrm{C} 1)$ is the biggest one, greater than 0.5 , following the electricity transmission and distribution tariff fluctuation risk criterion (C2), electricity transmission and distribution tariff matching risk (C4), and electricity transmission and distribution tariff fluctuation risk (C3), as shown in Figure 4. The risk criteria weighting result indicates that the electricity transmission and distribution tariff compliance risk (C1) is the most influential risk factor. The reason for this result lies in the fact that the electricity transmission and distribution cost classification and audit have been refined in the second round of electricity transmission and distribution tariff regulation, and the tariff setting standard and method for provincial electricity transmission and distribution have been defined and are much clearer, which make the electric power grid enterprise face much stricter 
electricity transmission and distribution tariff regulation. The electricity transmission and distribution tariff compliance risk will appear once the electric power grid enterprise cannot meet the relevant standards.

The optimal weights of four criteria

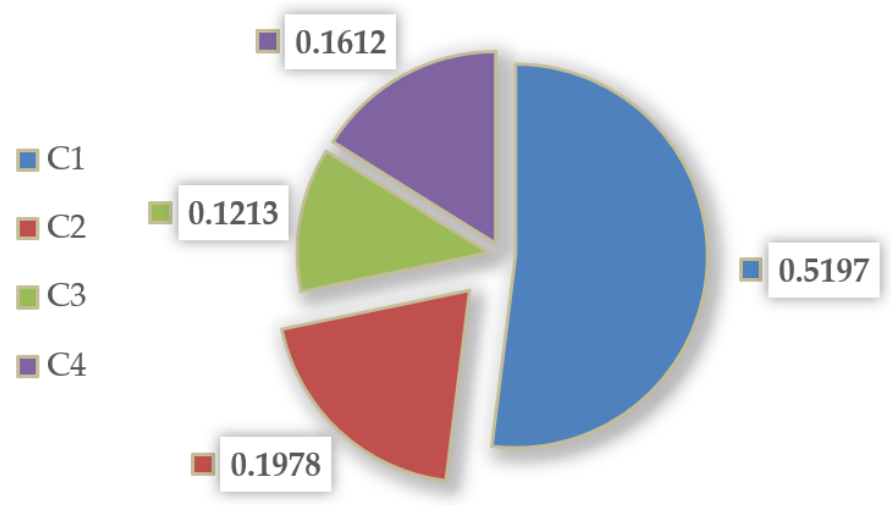

Figure 4. The optimal weights of four risk criteria.

For the risk sub-criteria related to each risk criteria, the power grid investment constraint risk (C12), required transmission and distribution cost drop risk (C21), electricity transmission and distribution cost implementation deviation risk (C32), and sustainable operational risk (C41), respectively, obtain the largest weights under each risk criteria frame, which are shown in Figure 5. The result indicates that, when evaluating and managing the risks that are faced by the electric power grid enterprise related to electricity transmission and distribution tariff regulation, these four risk sub-criteria should be taken into more consideration related to each risk criteria.

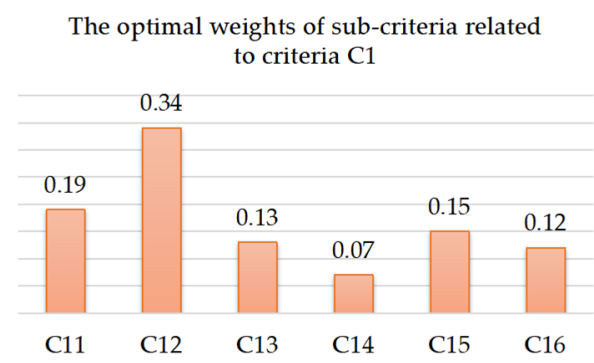

The optimal weights of sub-criteria related to criteria $\mathrm{C} 3$

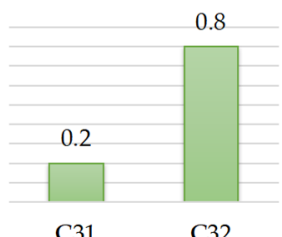

C31

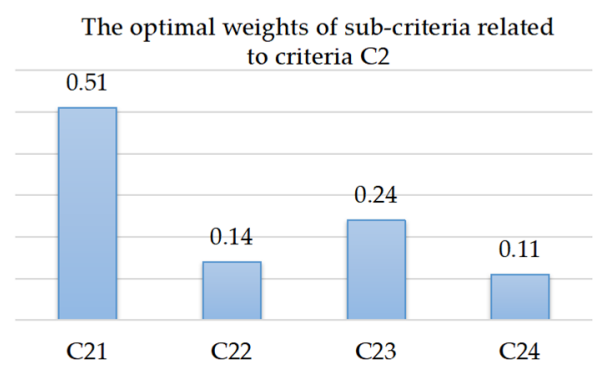

The optimal weights of sub-criteria related to criteria $\mathrm{C} 4$

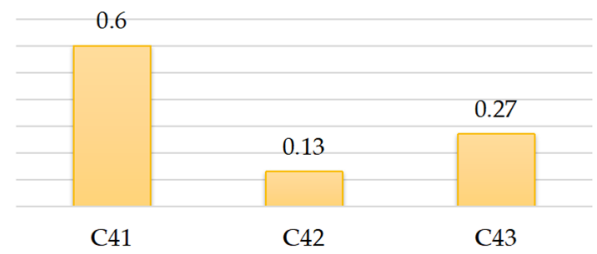

C41

C42

C43

Figure 5. The optimal weights of risk sub-criteria related to each risk criteria.

The expert panel evaluates the risk degree of each sub-criteria and the corresponding vague set evaluation matrix is obtained. When combined with the optimal weight of risk criteria and the vague set evaluation matrix of four risk criteria, four criteria risk grade and the comprehensive risk grade of electric power grid enterprise that are related to electricity transmission and distribution tariff regulation can be obtained, which are shown in Figure 6. It can be seen that the electricity transmission and distribution tariff compliance risk (C1) belongs to 'Very high' grade, and other three risks (namely electricity transmission and distribution tariff fluctuation risk criterion (C2), electricity transmission 
and distribution tariff fluctuation risk (C3), and electricity transmission and distribution tariff matching risk ( $\mathrm{C} 4)$ belong to 'High' risk. Meanwhile, $\mathrm{C} 1$ obtains the largest weight, followed by $\mathrm{C} 2, \mathrm{C} 4$, and $\mathrm{C} 3$. Overall, the comprehensive risk grade of this province-level electric power grid enterprise that is related to electricity transmission and distribution tariff regulation belongs to 'High' grade, but is very close to 'Very high' grade.

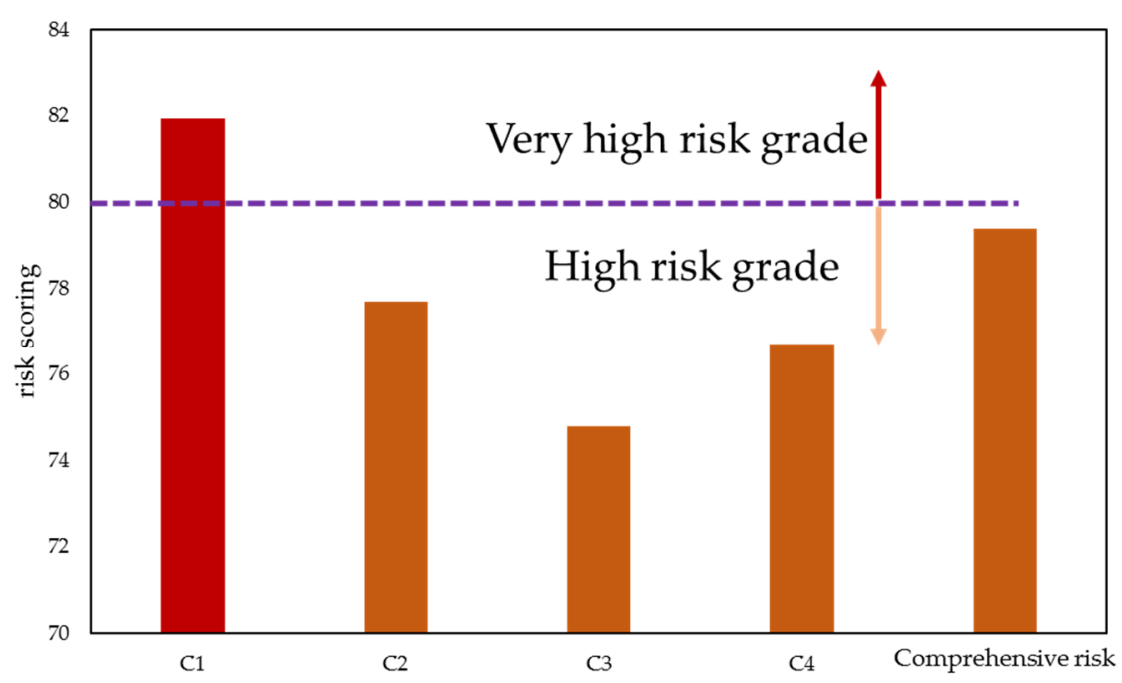

Figure 6. The risk grades of four criteria and the comprehensive risk grade.

\subsection{Comparative Analysis}

The proposed hybrid novel multi-criteria decision making (MCDM) method combining the FBWM and improved fuzzy comprehensive evaluation method based on the vague set in this paper will be compared with the MCDM method combining the FBWM and traditional fuzzy comprehensive evaluation method based on the fuzzy set.

For the risk evaluation of a province-level electric power grid enterprise located in Northern China related to electricity transmission and distribution tariff regulation by using the MCDM method combining the FBWM and traditional fuzzy comprehensive evaluation method based on fuzzy set, the risk grades are as the same as that of the proposed hybrid MCDM method shown in this paper. According to the performances (risk values) of all risk sub-criteria of province-level electric power grid enterprise, the corresponding fuzzy set evaluation matrix for four risk criteria are shown, as follow:

$$
\begin{gathered}
R_{11}=\left(\begin{array}{ccccc}
0 & 0 & 0.3 & 0.3 & 0.4 \\
0 & 0 & 0.2 & 0.4 & 0.4 \\
0 & 0 & 0.3 & 0.4 & 0.3 \\
0 & 0.3 & 0.3 & 0.4 & 0 \\
0 & 0 & 0.4 & 0.3 & 0.3 \\
0 & 0 & 0.2 & 0.5 & 0.3
\end{array}\right) \\
R_{21}=\left(\begin{array}{ccccc}
0 & 0.1 & 0.2 & 0.3 & 0.4 \\
0 & 0.2 & 0.4 & 0.2 & 0.2 \\
0 & 0 & 0.3 & 0.3 & 0.4 \\
0 & 0.3 & 0.3 & 0.3 & 0.1
\end{array}\right) \\
R_{31}=\left(\begin{array}{ccccc}
0 & 0 & 0.3 & 0.4 & 0.3 \\
0 & 0 & 0.5 & 0.3 & 0.2
\end{array}\right) \\
R_{41}=\left(\begin{array}{ccccc}
0 & 0 & 0.4 & 0.3 & 0.3 \\
0 & 0.1 & 0.4 & 0.3 & 0.2 \\
0 & 0 & 0.4 & 0.4 & 0.2
\end{array}\right)
\end{gathered}
$$


Depending on the optimal weights of the risk sub-criteria and the above fuzzy set evaluation matrix of four risk criteria, the risk grade for risk criteria can be calculated, as follow:

$$
\begin{gathered}
F_{11}=(0,0.020,0.3779,0.3337,0.3337) \\
F_{21}=(0,0.1124,0.2632,0.2855,0.3389) \\
F_{31}=(0,0,0.4599,0.3200,0.2201) \\
F_{41}=(0,0.0126,0.4,0.3276,0.2599)
\end{gathered}
$$

Subsequently, integrating the scoring function of each comment $V=\left(V_{1}, V_{2}, V_{3}, V_{4}, V_{5}\right)$ $=(20,40,60,80,100)$ and the weights of four risk criteria, the risk scoring of our risk criteria can be calculated, as follows:

$$
S_{11}=(80.51,77.02,75.20,76.7)
$$

Ultimately, the total risk scoring of this province-level electric power grid enterprise thatis related to electricity transmission and distribution tariff regulation is:

$$
S_{T 1}=\left(\mathrm{W}_{1}^{*}, \mathrm{~W}_{2}^{*}, \mathrm{~W}_{3}^{*}, \mathrm{~W}_{4}^{*}\right) * S_{11}^{T}=78.42
$$

It can be seen that the comprehensive risk grade of the province-level electric power grid enterprise that is related to electricity transmission and distribution tariff regulation by using the MCDM method combining the FBWM and traditional fuzzy comprehensive evaluation method based on fuzzy set is 'High'.

Therefore, the proposed hybrid MCDM method shown in this paper and the MCDM method combining the FBWM and traditional fuzzy comprehensive evaluation method based on fuzzy set obtain the same result in the risk evaluation of the province-level electric power grid enterprise related to electricity transmission and distribution tariff regulation. However, the proposed hybrid MCDM method shown in this paper can not only obtain the comprehensive risk grade, but also consider the differences between the experts. Thus, the proposed hybrid MCDM method combining the FBWM and fuzzy comprehensive evaluation method based on the vague set in this paper for risk evaluation of the provincelevel electric power grid enterprise related to electricity transmission and distribution tariff regulation is more feasible and practical.

\subsection{Similarity Analysis}

In this section, the similarity between the ranking of ranking importance of the criteria and sub-criteria between each expert has been computed by using the WS coefficient.

Tables 7-11 present the final results, which show the ranking that is determined by the experts and final ranking of the criteria and the sub-criteria, as well as the WS coefficients. For WS Coefficients in the criteria, three experts obtain a high value in WS coefficient, which are more than 0.682 , while the remaining experts have medium WS value, both are 0.67 , which indicates that the final ranking of the criteria is practical. For WS Coefficients in the sub-criteria, only the WS coefficient of Expert 3 ranking the $\mathrm{C} 32$ and Experts 5 ranking the $\mathrm{C} 43$ are 0.25 and 0.37 , respectively, which suggest the low similarity. The reason is that the value of the coefficients depending on the length of the ranking, the lower the length of the ranking, the sharper the WS values will decrease when replacing the best elements with the second, third, fourth, and fifth ones [36]. The WS coefficients ranking other sub-criteria by experts are among 0.61 and 1 , which indicate that the final ranking of the criteria is also comprehensively practical. 
Table 7. The WS coefficients of the criteria.

\begin{tabular}{ccccccc}
\hline Criteria & $\begin{array}{c}\text { The Final Ranking of } \\
\text { the Criteria }\end{array}$ & Expert 1 & Expert 2 & Expert 3 & Expert 4 & Expert 5 \\
\hline C1 & 1 & 1 & 2 & 1 & 1 & 2 \\
C2 & 2 & 2 & 1 & 3 & 2 & 1 \\
C3 & 4 & 3 & 4 & 4 & 4 & 4 \\
C4 & 3 & 4 & 3 & 2 & 3 & 3 \\
WS & & 0.93 & 0.67 & 0.81 & 1 & 0.67 \\
\hline
\end{tabular}

Table 8. The WS coefficients of the sub-criteria of $\mathrm{C} 1$.

\begin{tabular}{ccccccc}
\hline Sub-Criteria & $\begin{array}{c}\text { The Final Ranking of } \\
\text { the Criteria }\end{array}$ & Expert 1 & Expert 2 & Expert 3 & Expert 4 & Expert 5 \\
\hline C11 & 2 & 2 & 3 & 4 & 1 & 2 \\
C12 & 1 & 1 & 1 & 1 & 2 & 3 \\
C13 & 4 & 3 & 2 & 5 & 3 & 4 \\
C14 & 6 & 6 & 6 & 6 & 4 & 5 \\
C15 & 3 & 4 & 5 & 2 & 5 & 1 \\
C16 & 5 & 5 & 4 & 3 & 6 & 6 \\
WS & & 0.94 & 0.77 & 0.81 & 0.73 & 0.61 \\
\hline
\end{tabular}

Table 9. The WS coefficients of the sub-criteria of $\mathrm{C} 2$.

\begin{tabular}{lcccccc}
\hline Criteria & $\begin{array}{c}\text { The Final Ranking of } \\
\text { the Criteria }\end{array}$ & Expert 1 & Expert 2 & Expert 3 & Expert 4 & Expert 5 \\
\hline C21 & 1 & 1 & 1 & 1 & 1 & 1 \\
C22 & 2 & 3 & 2 & 3 & 4 & 2 \\
C23 & 4 & 4 & 4 & 4 & 3 & 3 \\
C24 & 3 & 2 & 3 & 2 & 2 & 4 \\
WS & & 0.81 & 1 & 0.81 & 0.770 & 0.93 \\
\hline
\end{tabular}

Table 10. The WS coefficients of the sub-criteria of C3.

\begin{tabular}{ccccccc}
\hline Criteria & $\begin{array}{c}\text { The Final Ranking of } \\
\text { the Criteria }\end{array}$ & Expert 1 & Expert 2 & Expert 3 & Expert 4 & Expert 5 \\
\hline C31 & 2 & 2 & 2 & 1 & 2 & 2 \\
C32 & 1 & 1 & 1 & 2 & 1 & 1 \\
WS & & 1 & 1 & 0.25 & 1 & 1 \\
\hline
\end{tabular}

Table 11. The WS coefficients of the sub-criteria of C4.

\begin{tabular}{lcccccc}
\hline Criteria & $\begin{array}{c}\text { The Final Ranking of } \\
\text { the Criteria }\end{array}$ & Expert 1 & Expert 2 & Expert 3 & Expert 4 & Expert 5 \\
\hline C41 & 1 & 1 & 1 & 1 & 1 & 2 \\
C42 & 3 & 2 & 3 & 3 & 2 & 3 \\
C43 & 2 & 3 & 2 & 2 & 3 & 1 \\
WS & & 0.75 & 1 & 1 & 0.75 & 0.375 \\
\hline
\end{tabular}

\section{Conclusions}

The electricity transmission and distribution tariff reform has been the core and important task for the new round of electric power system reform since 2015 in China, and the electricity transmission and distribution tariff regulation has gone to the second round. Currently, the electric power grid enterprises are facing a closed-loop regulatory system and increasingly strict regulatory environment, which will bring risks to the sustainable 
operation and development of electric power grid enterprises. Therefore, it is urgent to evaluate the risk of electric power grid enterprise that is related to electricity transmission and distribution tariff regulation, which can aid the electricity regulators and electric power grid enterprise operators to identify and avoid the related risk, as well as enabling the electric power grid enterprise to obtain smoother and more sustainable development.

In this paper, a hybrid novel MCDM method for risk evaluation of electric power grid enterprise that is related to electricity transmission and distribution tariff regulation is proposed combining the FBWM for determining the optimal weights of risk criteria and improved fuzzy comprehensive evaluation method based on vague set for ranking the comprehensive risk grade of electric power grid enterprise. The empirical analysis focusing on the risk of a province-level electric power grid enterprise that is located in Northern China is performed, and the result indicates that the current comprehensive risk grade of this province-level electric power grid enterprise related to electricity transmission and distribution tariff regulation belongs to 'High', but it is very close to 'Very high'. For the specific risk, the grade of electricity transmission and distribution tariff compliance risk belongs to 'Very high', while the grades of electricity transmission and distribution tariff fluctuation risk, electricity transmission and distribution tariff fluctuation risk, and electricity transmission and distribution tariff matching risk all belong to 'High'. The result indicates the province-level electric power grid enterprise in China is facing high risk under current strict electricity transmission and distribution tariff regulation, which should establish effective risk management system on the basis of its own situation, so as to identify the risk and control the risk related to the electricity transmission and distribution tariff regulation in a more timely manner, and finally adapt to the increasingly strict electricity transmission and distribution tariff regulation environment in China.

Although the proposed hybrid MCDM method combining the FBWM and the improved fuzzy comprehensive evaluation method based on a vague set for risk evaluation of electric power grid enterprise related to electricity transmission and distribution tariff regulation has been verified to be feasible and applicable, considering the increasingly strict electricity transmission and distribution tariff regulation environment in China and uncertainties of electricity marketization reform, the risk criteria of electric power grid enterprise related to electricity transmission and distribution tariff regulation should be updated regularly, and the related authorities also have the duty to carry out some policies to ease the risk level of the electricity marketplace, so as to aid the electric power grid enterprise to go through those risks, which enables them to make profits and improve their quality in management and service. In this paper, the important risk factors have been identified, such as the electricity transmission and distribution tariff compliance risk and electricity transmission and distribution tariff fluctuation risk in the risk criteria level, and the power grid investment constraint risk, required transmission and distribution cost drop risk, electricity transmission, and distribution cost implementation deviation risk and sustainable operational risk in the risk sub-criteria level, which should be paid greater attention in the establishment of risk management system. The risk handling measurement for electric power grid enterprise that is related to electricity transmission and distribution tariff regulation will be studied in depth in the following research. However, the proposed hybrid MCDM method presented in this paper can also be employed for the risk evaluation of other provincial electric power grid enterprises in China and risk evaluation in other issues that are related to electric power system reform.

Author Contributions: Conceptualization, P.Y., Z.X. and S.G.; Data curation, B.L.; Formal analysis, W.L., B.L. and P.Y.; Funding acquisition, S.G.; Investigation, B.L., R.F., Y.Z. and Z.X.; Methodology, W.L., B.L. and S.G.; Project administration, B.L. and S.G.; Resources, R.F., P.Y., Y.Z. and Z.X.; Software, W.L. and Y.Z.; Validation, R.F. and P.Y.; Visualization, W.L. and Z.X.; Writing-original draft, W.L. and B.L.; Writing—review \& editing, S.G. All authors have read and agreed to the published version of the manuscript. 
Funding: This research was funded by the project "Theory, technology and application on regulatory risk management and information disclosure of power grid enterprises under electricity transmission and distribution tariff reform" of the Science and Technology Project of the State Grid Corporation of China (1400-201957285A-0-0-00).

Institutional Review Board Statement: Not applicable.

Informed Consent Statement: Not applicable.

Data Availability Statement: Not applicable.

Acknowledgments: This research was funded by the project "Theory, technology and application on regulatory risk management and information disclosure of power grid enterprises under electricity transmission and distribution tariff reform" of the Science and Technology Project of the State Grid Corporation of China (1400-201957285A-0-0-00). The authors are grateful to the editor and anonymous reviewers for their work.

Conflicts of Interest: The authors declare no conflict of interest.

\section{References}

1. Zeng, M.; Yang, Y.Q.; Wang, L.H.; Sun, J.H. The power industry reform in China 2015: Policies, evaluations and solutions. Renew. Sust. Energ. Rev. 2016, 57, 94-110. [CrossRef]

2. Guo, S.; Zhang, W.Y.; Gao, X. Business Risk Evaluation of Electricity Retail Company in China Using a Hybrid MCDM Method. Sustainability 2020, 12, 2040. [CrossRef]

3. Yang, Y.X.; Faruqui, A. Reducing electricity prices and establishing electricity markets in China: Dos and don'ts. Electr. J. 2019, 32, 106633. [CrossRef]

4. Zhou, H.; Su, Y.; Chen, Y.; Ma, Q.; Mo, W. The China southern power grid: Solutions to operation risks and planning challenges. IEEE Power Energy Mag. 2016, 14, 72-78. [CrossRef]

5. Wang, S.X.; Zheng, W.D.; Deng, C.; Xu, H.D.; Wan, S.W.; Chen, K.; Zhao, J.Y. Grid enterprise operational risk identification and assessment model. Appl. Mech. Mater. 2014, 521, 786-792. [CrossRef]

6. Li, C.; Li, P.; Feng, X. Analysis of wind power generation operation management risk in China. Renew. Energy 2014, 64, 266-275. [CrossRef]

7. Hasda, E.K.; Sumirat, E. Risk management of logistic department of electricity company. INOVASI 2018, 14, 98-112. [CrossRef]

8. Pop, I.T.; Raducanu, F.; Munteanu, C. Recent Developments Concerning the Investment Works Risk Management in the Romanian Power Grid Company-Transelectrica SA. Acta Electroteh. 2015, 56, 272-275.

9. Lin, Y.; Li, F.C.; Wang, Q.L.; Qilong, L. Risk Assessment and Prevention of Implementation of Internal Energy Saving Services in Power Grid. In Proceedings of the 2nd IEEE Advanced Information Management, Communicates, Electronic and Automation Control Conference (IMCEC), Xi'an, China, 25-27 May 2018; pp. 2213-2217.

10. Sasaki, D.; Nakayama, M. Risk management in an electricity transmission project between Iceland and the UK. Int. J. Soc. Sci. Stud. 2016, 4, 17. [CrossRef]

11. Bhattacharya, A.; Kojima, S. Power sector investment risk and renewable energy: A Japanese case study using portfolio risk optimization method. Energy Policy 2012, 40, 69-80. [CrossRef]

12. Duan, Y.; Sun, Y.; Zhang, Y.; Fan, X.; Dong, Q.; Guo, S. Risk Evaluation of Electric Power Grid Investment in China Employing a Hybrid Novel MCDM Method. Mathematics 2021, 9, 473. [CrossRef]

13. Maziku, H.; Shetty, S.; Nicol, D.M. Security risk assessment for SDN-enabled smart grids. Comput. Commun. 2019, 133, 1-11. [CrossRef]

14. Cardenas, D.J.S.; Hahn, A.; Liu, C.C. Assessing Cyber-Physical Risks of IoT-Based Energy Devices in Grid Operations. IEEE Access 2020, 8, 61161-61173. [CrossRef]

15. Case, D.U. Analysis of the cyber attack on the Ukrainian power grid. Electr. Inf. Shar. Anal. Cent. 2016, 388, 10-18.

16. Onyeji, I.; Bazilian, M.; Bronk, C. Cyber security and critical energy infrastructure. Electr. J. 2014, 27, 52-60. [CrossRef]

17. Wang, C.N.; Tsai, H.T.; Ho, T.P.; Nguyen, V.T.; Huang, Y.F. Multi-criteria decision making (MCDM) model for supplier evaluation and selection for oil production projects in Vietnam. Processes 2020, 8, 134. [CrossRef]

18. Ghasempour, R.; Nazari, M.A.; Ebrahimi, M.; Ahmadi, M.H.; Hadiyuanto, H. Multi-Criteria Decision Making (MCDM) Approach for Selecting Solar Plants Site and Technology: A Review. Int. J. Renew. Energy Dev. 2019, 8, 15-25. [CrossRef]

19. Wu, Y.; Xu, C.; Zhang, T. Evaluation of renewable power sources using a fuzzy MCDM based on cumulative prospect theory: A case in China. Energy 2018, 147, 1227-1239. [CrossRef]

20. Lee, H.C.; Chang, C.T. Comparative analysis of MCDM methods for ranking renewable energy sources in Taiwan. Renew. Sustain. Energy Rev. 2018, 92, 883-896. [CrossRef]

21. Azhar, M.; Ullah, K. MCDM Analysis of Renewable and Conventional Energy Power Plants in Pakistan. In Proceedings of the 3rd International Conference on Computing, Mathematics and Engineering Technologies (iCoMET), Sukkur, Pakistan, 29-30 January 2020; pp. 1-6. 
22. Sedady, F.; Beheshtinia, M.A. A novel MCDM model for prioritizing the renewable power plants' construction. Manag. Environ. Qual. 2019, 30, 383-399.

23. Guo, S.; Zhao, H. Fuzzy best-worst multi-indexes decision-making method and its applications. Knowl. Based Syst. 2017, 121, 23-31. [CrossRef]

24. Chen, Z.; Ming, X.; Zhou, T.; Chang, Y.; Sun, Z. A hybrid framework integrating rough-fuzzy best-worst method to identify and evaluate user activity-oriented service requirement for smart product service system. J. Clean. Prod. 2020, 253, 119954. [CrossRef]

25. Amiri, M.; Hashemi-Tabatabaei, M.; Ghahremanloo, M.; Keshavarz Ghorabaee, M.; Zavadskas, E.K.; Banaitis, A. A new fuzzy BWM approach for evaluating and selecting a sustainable supplier in supply chain management. Int. J. Sustain. Dev. World Ecol. 2020, 28, 125-142. [CrossRef]

26. Moharrami, M.; Naboureh, A.; Gudiyangada, N.T.; Ghorbanzadeh, O.; Guan, X.; Blaschke, T. National-scale landslide susceptibility mapping in Austria using fuzzy best-worst multi-indexes decision-making. ISPRS Int. J. Geo-Inf. 2020, 9, 393. [CrossRef]

27. Khanmohammadi, E.; Zandieh, M.; Tayebi, T. Drawing a strategy canvas using the fuzzy best-worst method. Glob. J. Flex. Syst. Manag. 2019, 20, 57-75. [CrossRef]

28. Gau, W.L.; Buehrer, D.J. Vague set. IEEE Trans. Syst. Man Cybern. 1993, 23, 610-614. [CrossRef]

29. Lu, S.; Bao, H.; Pan, H. Urban water security evaluation based on similarity measure model of Vague set. Int. J. Hydrog. Energy 2016, 41, 15944-15950. [CrossRef]

30. Zeng, S.; Lin, Z.; Wen, F.; Ledwich, G. A new approach for power system black-start decision-making with vague set theory. Int. J. Electr. Power Energy Syst. 2012, 34, 114-120. [CrossRef]

31. Elzarka, H.M.; Yan, H.; Chakraborty, D. A vague set fuzzy multi-attribute group decision-making model for selecting onsite renewable energy technologies for institutional owners of constructed facilities. Sustain. Cities Soc. 2017, 35, 430-439. [CrossRef]

32. Liu, Y.; Li, F.Y.; Wang, Y.; Yu, X.; Yuan, J.; Wang, Y. Assessing the environmental impact caused by power grid projects in high altitude areas based on BWM and Vague sets techniques. Sustainability 2018, 10, 1768. [CrossRef]

33. Sałabun, W.; Jarosaw, W.; Shekhovtsov, A. Are MCDA Methods Benchmarkable? A Comparative Study of TOPSIS, VIKOR, COPRAS, and PROMETHEE II Methods. Symmetry 2020, 12, 1549. [CrossRef]

34. Kizielewicz, B.; Sałabun, W. A New Approach to Identifying a Multi-Criteria Decision Model Based on Stochastic Optimization Techniques. Symmetry 2020, 12, 1551. [CrossRef]

35. Faizi, S.; Sałabun, W.; Ullah, S.; Rashid, T.; Wieckowski, J. A new method to support decision-making in an uncertain environment based on normalized interval-valued triangular fuzzy numbers and comet technique. Symmetry 2020, 12, 516. [CrossRef]

36. Ghoushchi, S.J.; Yousefi, S.; Khazaeili, M. An extended FMEA approach based on the Z-MOORA and fuzzy BWM for prioritization of failures. Appl. Soft Comput. 2019, 81, 105505. [CrossRef]

37. Omrani, H.; Alizadeh, A.; Emrouznejad, A. Finding the optimal combination of power plants alternatives: A multi response Taguchi-neural network using TOPSIS and fuzzy best-worst method. J. Clean. Prod. 2018, 203, 210-223. [CrossRef]

38. Rahimi, S.; Hafezalkotob, A.; Monavari, S.M.; Rahimi, R.; Hafezalkotob, A. Sustainable landfill site selection for municipal solid waste based on a hybrid decision-making approach: Fuzzy group BWM-MULTIMOORA-GIS. J. Clean. Prod. 2020, $248,119186$. [CrossRef]

39. Karimi, H.; Sadeghi-Dastaki, M.; Javan, M. A fully fuzzy best-worst multi attribute decision making method with triangular fuzzy number: A case study of maintenance assessment in the hospitals. Appl. Soft Comput. 2020, 86, 105882. [CrossRef]

40. Cheng, L.; Hu, Z.; Lou, S. Improved methods for fuzzy comprehensive evaluation of the reclamation suitability of abandoned mine lands. Int. J. Min. Reclam. Environ. 2017, 31, 212-229. [CrossRef]

41. Bustince, H.; Burillo, P. Vague sets are intuitionistic fuzzy sets. Fuzzy Sets Syst. 1996, 79, 403-405. [CrossRef]

42. Sałabun, W.; Urbaniak, K. A new coefficient of rankings similarity in decision-making problems. In Proceedings of the International Conference on Computational Science, Amsterdam, The Netherland, 3-5 June 2020; Springer: Cham, Switzerland, 2020; pp. 632-645. 